\title{
Re-calculation of the attenuation functions for Local Magnitude from the upgraded Central Weather Bureau Seismic Network in Taiwan
}

\author{
Zhuo-Kang Guan ${ }^{1}$, Hao Kuo-Chen ${ }^{1, *}$, and Wei-Fang Sun ${ }^{2}$ \\ ${ }^{1}$ Department of Earth Sciences, National Central University, Taoyuan City, Taiwan \\ ${ }^{2}$ Department of Natural Resources and Environmental Studies, National Dong Hwa University, Hualien County, Taiwan
}

\author{
Article history: \\ Received 27 November 2019 \\ Revised 16 June 2020 \\ Accepted 16 June 2020 \\ Keywords: \\ Local magnitude, Attenuation \\ function, Moment magnitude, Taiwan \\ Citation: \\ Guan, Z.-K., H. Kuo-Chen, and \\ W.-F. Sun, 2020: Re-calculation of \\ the attenuation functions for Local \\ Magnitude from the upgraded Central \\ Weather Bureau Seismic Network \\ in Taiwan. Terr. Atmos. Ocean. \\ Sci., 31, 479-486, doi: 10.3319 / \\ TAO.2020.06.16.01
}

\begin{abstract}
The empirical attenuation functions for Local Magnitude $\left(\mathrm{M}_{\mathrm{L}}\right)$ currently used in Taiwan have been known for overestimated magnitudes around 0.2 compared with moment magnitude $\left(\mathrm{M}_{\mathrm{W}}\right)$ for shallow earthquakes (depths $\leq 35 \mathrm{~km}$ ). Moreover, for deep earthquakes (depths $>35 \mathrm{~km}$ ), $\mathrm{M}_{\mathrm{L}}(>6)$ can be larger than $\mathrm{M}_{\mathrm{W}}$ around 0.5. Based on global observations and seismological theory, $\mathrm{M}_{\mathrm{L}}$ is equal to $\mathrm{M}_{\mathrm{W}}$ for magnitudes $4-6$, whereas $M_{L}$ is smaller than $M_{W}$ for magnitudes $>6$. This indicates that the attenuation functions for the Taiwan region need to be re-calculated. In this study, we used the new data set collected at the upgraded Central Weather Bureau Seismic Network (CWBSN24) from January 2012 to April 2019 and totally there are 692 events with $\mathrm{M}_{\mathrm{L}} \geq 3$ and 35228 amplitude data used for analysis. To accommodate the complicated tectonic environment in Taiwan, there are four attenuation functions, $\log A_{0}(\Delta)$, based on the focal depths and hypocentral distances, which are:

$\log A_{0}(\Delta)=\left\{\begin{array}{cc}-0.00401 R-\log R-0.58 & (0 \mathrm{~km}<\Delta \leq 80 \mathrm{~km}) \\ -0.00234 R-0.83 \log R-1.11 & (80 \mathrm{~km}<\Delta)\end{array}\right.$

for shallow earthquakes (focal depth, $h \leq 35 \mathrm{~km}$ ), and

$\log A_{0}(\Delta)= \begin{cases}-0.00077 R-0.83 \log R-1.26 & \left(\text { Latitude } \geq 23^{\circ} \mathrm{N}\right) \\ -0.00176 R-0.83 \log R-1.16 & \left(\text { Latitude }<23^{\circ} \mathrm{N}\right)\end{cases}$

for deep earthquakes $(h>35 \mathrm{~km})$,

where $\Delta$ is epicentral distance, $R\left(=\sqrt{\Delta^{2}+h^{2}}\right)$ is hypocentral distance. $\mathrm{M}_{\mathrm{L}}$ calculated by using the old attenuation functions for deep and large $\left(\mathrm{M}_{\mathrm{L}}>5.5\right)$ earthquakes is larger than that by using the new ones about 0.4 . With the new empirical attenuation functions, the relationship between $\mathrm{M}_{\mathrm{L}}$ and $\mathrm{M}_{\mathrm{W}}$ follows the global observations and also the new $\mathrm{M}_{\mathrm{L}}$ avoids the confusion for the public when releasing the official earthquake reports.
\end{abstract}

\section{INTRODUCTION}

The current official operation for calculation of Local Magnitude $\left(\mathrm{M}_{\mathrm{L}}\right)$ in Taiwan is according to the empirical formulas proposed by Shin (1993), which used the simulated Wood-Anderson seismograms converted from the three-components short-period seismograms of the Central Weather Bureau Seismic Network (CWBSN) from September 1991 to February 1992. It has been reported that the values of $\mathrm{M}_{\mathrm{L}}$ are larger than those of moment magnitude $\left(\mathrm{M}_{\mathrm{W}}\right)$ around 0.2 for shallow earthquakes $(\leq 35 \mathrm{~km})$,

\footnotetext{
* Corresponding author

E-mail:kuochen@g.ncu.edu.tw
}

in general (Wu et al. 2005). Moreover, not only for shallow earthquakes but for deeper ones, the values of $\mathrm{M}_{\mathrm{L}}$ are much larger than those of $\mathrm{M}_{\mathrm{w}}$. For example, on $31^{\text {th }}$ May 2016, there was an earthquake occurred in northeastern offshore of Taiwan. The focal depth and $\mathrm{M}_{\mathrm{L}}$ reported by the Central Weather Bureau, Taiwan (CWB) are $256.9 \mathrm{~km}$ and 6.9, respectively, but meanwhile the depth and $\mathrm{M}_{\mathrm{W}}$ reported by the U.S. Geological Survey (USGS) are $246.4 \mathrm{~km}$ and 6.4 . The difference between these two magnitudes is 0.5 . This is an unusual case because $M_{L}$ greater than 6 is saturated and smaller than $M_{W}$ owing to only high frequency $(\geq 2 \mathrm{~Hz}$ ) energy measured by $\mathrm{M}_{\mathrm{L}}$ (Kanamori 1983). This indicates 
that the current empirical formulas have systematic biases and need to be re-calculated the attenuation functions for the calculation of $\mathrm{M}_{\mathrm{L}}$. With the new empirical formulas, the calculation of $\mathrm{M}_{\mathrm{L}}$ can reduce the gap between $\mathrm{M}_{\mathrm{L}}$ and $\mathrm{M}_{\mathrm{W}}$ and avoid the confusion for the public when releasing the official earthquake reports. In this study, in order to obtain new attenuation functions, we used the data set of 692 earthquakes $\left(M_{L} \geq 3\right)$ from the upgraded Central Weather Bureau Seismic Network (CWBSN24) from January 2012 to April 2019.

\section{DATA AND ANALYSIS}

The old seismic network, CWBSN, is with 12-bit A/D converter and the timestamps were given after the data were transmitted to the center, which both caused the averaged time delay and shifted earthquake origin times around $0.2 \mathrm{~s}$ (Chang et al. 2012). Because of this reason, since 2012, the three-components short-period seismic network of the CWB, which consists of 71 stations, has been fully upgraded with 24-bit A/D converter and on-site GPS timestamp, called CWBSN24 (Fig. 1a). In this study, we selected the earthquake list from the CWB earthquake catalogue based on four criteria: (1) $\mathrm{M}_{\mathrm{L}} \geq 3$; (2) region within longitude $120^{\circ}$ - $124^{\circ} \mathrm{E}$ and latitude $20^{\circ}-26^{\circ} \mathrm{N}$; (3) time period from January 2012 to April 2019; and (4) earthquakes also listed in the USGS earthquake catalogue for further $\mathrm{M}_{\mathrm{L}}$ comparison with $M_{W}$ or mb. Totally, there are 692 events with 35228 maximum amplitudes from 71 stations (Fig. 1b). The amplitudes calculated from the simulated Wood-Anderson seismograms from short-period seismograms as described in Shin (1993). The maximum amplitude from each station is determined by the root sum squared of peak amplitudes in the NS and EW components (Shin 1993), which is the official procedure for data processing in the CWB. Previous global studies have shown the relationship between $\mathrm{M}_{\mathrm{W}}$ and $\mathrm{M}_{\mathrm{L}}$ : $\mathrm{M}_{\mathrm{W}}$ is larger than $M_{L}$ for magnitudes larger than $6, M_{W}$ is equal to $M_{L}$ for magnitudes from 4 to 6 , and for smaller magnitudes (2 - 4) $\mathrm{M}_{\mathrm{W}}$ is around $0.67 \mathrm{M}_{\mathrm{L}}$ (Kanamori 1983; Deichmann 2006; Havskov and Ottemöller 2010). However, $M_{W}$ versus $M_{L}$ plot (Fig. 2) for the Taiwan region shows that $\mathrm{M}_{\mathrm{W}}$ greater than 4.5 is systematically lower than $\mathrm{M}_{\mathrm{L}}$, which is different with previous global studies (Kanamori 1983; Hanks and Boore 1984; Havskov and Ottemöller 2010). This highlights the need for re-calculation of the attenuation functions.

$\mathrm{M}_{\mathrm{L}}$ is widely used for local seismic network and originally proposed by Richter (1935) as:

$\mathrm{M}_{\mathrm{L}}=\log A-\log A_{0}(\Delta)$

where $A$ is the maximum amplitude in millimeters recorded on the standard Wood-Anderson seismograph, $\Delta$ is an epicentral distance, and $A_{0}$ is the attenuation function, which relates to geometrical spreading, anelastic attenuation, and wave scattering. $\log A_{0}$ is empirically determined and strongly depends on the tectonic regions. Based on the focal depth $(h)$ and epicentral distance $(\Delta)$ of earthquakes, Shin (1993) has first proposed three $\log A_{0}(\Delta)$ functions for the Taiwan area:

$\log A_{0}(\Delta)=$
$\left\{\begin{array}{cc}-0.00716 R-\log R-0.39 & (0 \mathrm{~km}<\Delta \leq 80 \mathrm{~km}) \\ -0.00261 R-0.83 \log R-1.07 & (80 \mathrm{~km}<\Delta)\end{array}\right.$

for shallow earthquakes $(h \leq 35 \mathrm{~km})$ and

$\log A_{0}(\Delta)=-0.00326 R-0.83 \log R-1.01$

for deep earthquakes $(h>35 \mathrm{~km})$ where $R\left(=\sqrt{\Delta^{2}+h^{2}}\right)$ is the hypocentral distance.

$\mathrm{Wu}$ et al. (2005) has found that at shallow depths $(h \leq 35 \mathrm{~km}) \mathrm{M}_{\mathrm{L}}$ is larger than $\mathrm{M}_{\mathrm{W}}$ by using the $\log A_{0}(\Delta)$ [Eqs. (2) and (3)] of Shin (1993) for calculation. Therefore, Wu et al. (2005) used a regression model between $M_{L}$ and $\mathrm{M}_{\mathrm{W}}$ from the data set of the Taiwan Strong Motion Instrumental Program (TSMIP) to obtain a new $\log A_{0}$ :

$\log A_{0}(R)=0.332-1.568 \log R \pm 0.280$

A maximum amplitude $[A(\Delta)]$ of $\mathrm{S}$ wave recorded in a seismograph is affected by the factors of source, path, and site effects, and can be expressed as

$A(\Delta)=C R^{-n} e^{-\gamma R} S$

where $\gamma$ and $n$ are the attenuation and geometrical spreading coefficients, respectively, and $C$ and $S$ are source-related and site-dependent constants, respectively. We can take logarithm on both sides of Eq. (5) as

$\log \left[A(\Delta) R^{n}\right]=-0.4343 \gamma R+\log C+\log S$

In the left hand side, the reduced amplitude, of Eq. (6) has a linear relationship with the hypocentral distance $R$. Therefore, $\gamma$ can be simply determined from the slope of the linear regression of the data. The terms $C$ and $S$ are the intercept of the linear regression of the data, which are the combination effects. According to $\log A_{0}(\Delta=100)=-3$, which is the definition of $\mathrm{M}_{\mathrm{L}}$ by Richter (1935), we can obtain $\log C$ to have the attenuation functions, $\log A_{0}(\Delta)$. The term $\log S$ is the residual term, as $\Delta \mathrm{M}_{\mathrm{L}}$, from the average for each station and will be mentioned in Discussion section. 


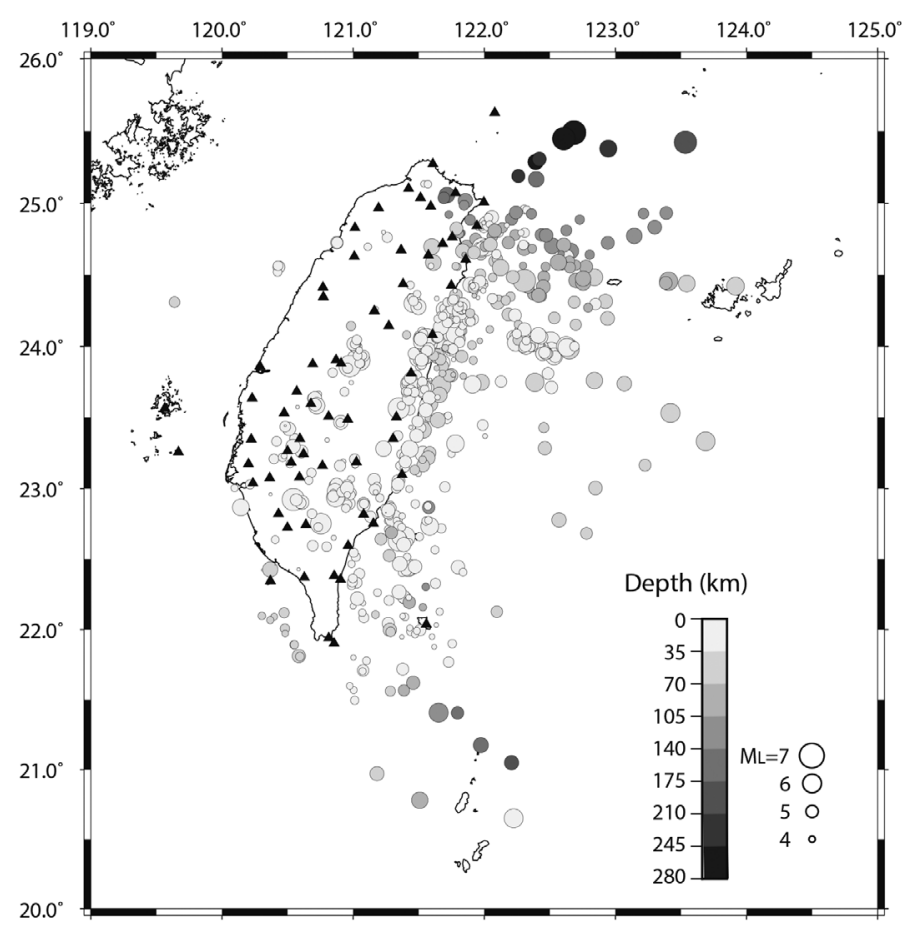

Fig. 1. The distributions of seismic stations (black triangles) and earthquakes (circles) used in this study.

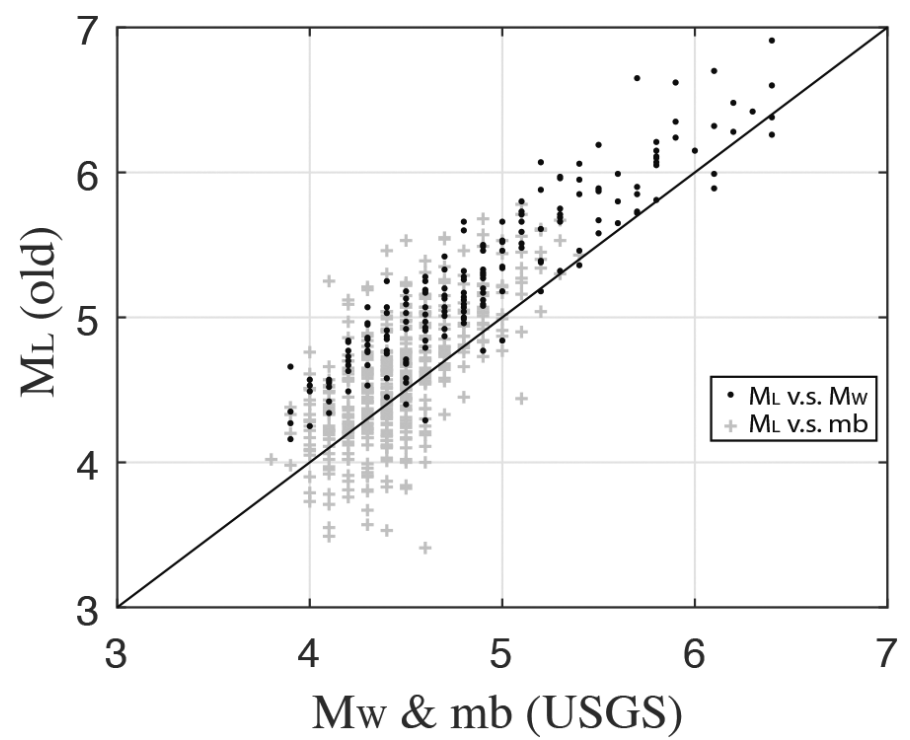

Fig. 2. The comparison of $M_{L}$ (old) and $M_{W}$ and mb. $M_{L}$ (old): $M_{L}$ determined from the attenuation functions from Shin (1993). 


\section{RESULTS}

Based on the focal depths and epicentral distances, there are three attenuation functions applied in the Taiwan area [Eqs. (2) to (3)] (Shin 1993). In this study, we have further divided deep earthquakes into northern and southern parts to reflect the different tectonic environments of the Ryukyu and Manila subductions zones, respectively. Totally, there are four regimes and the $n$ value is set to 1 for shallow $(h \leq 35 \mathrm{~km})$ and near-distance $(0 \mathrm{~km}<\Delta \leq 80 \mathrm{~km})$ earthquakes and for other regimes the $n$ values are set to 0.83 for considering $L g$ wave propagation (Shin 1993). The results of the 4 cases based on the earthquake depths and epicentral distances are shown as follows:

\section{Case 1: $\boldsymbol{h} \leq \mathbf{3 5} \mathrm{km}$ and $0 \mathrm{~km}<\boldsymbol{\Delta} \leq \mathbf{8 0} \mathrm{km}$}

In total, 488 events with 5488 amplitudes are used for regression. The slope obtained from the relationship between the reduced amplitude and hypocentral distance based on Eq. (6) is 0.00923 and $\gamma$ is $0.00401 \mathrm{~km}^{-1}$ (Fig. 3a). After applied the definition of $\log A_{0}(\Delta=100)=-3$, the attenuation function (Fig. 4) is

$\log A_{0}(\Delta)=-0.00401 R-\log R-0.58$

\section{Case 2: $h \leq 35 \mathrm{~km}$ and $80 \mathrm{~km}<\Delta$}

517 events with 20260 amplitudes are used for regression and the slope and $\gamma$ are 0.00539 and $0.00234 \mathrm{~km}^{-1}$, respectively (Fig. 3b). The attenuation function (Fig. 4) for this case is

$\log A_{0}(\Delta)=-0.00234 R-0.83 \log R-1.11$

\section{Case 3: $h>35 \mathrm{~km}$ and earthquakes located in latitude $\geq 23^{\circ} \mathrm{N}$}

150 events with 7824 amplitudes are used for regression and obtained the slope and $\gamma$ are 0.00177 and $0.00077 \mathrm{~km}^{-1}$, respectively (Fig. 3c). The attenuation function (Fig. 4) is

$\log A_{0}(\Delta)=-0.00077 R-0.83 \log R-1.26$

\section{Case 4: $h>35 \mathrm{~km}$ and earthquakes located in latitude $<23^{\circ} \mathrm{N}$}

33 events with 1656 amplitudes are used for regression and the slope and $\gamma$ are 0.00405 and $0.00176 \mathrm{~km}^{-1}$, respectively (Fig. 3d). The attenuation function (Fig. 4) is

$$
\log A_{0}(\Delta)=-0.00176 R-0.83 \log R-1.16
$$

\section{DISCUSSION}

For the comparison between the new and old attenua- tion functions (Fig. 4), the Eqs. (7) and (8) of Cases 1 and 2 obtained in this study are similar to the Eqs. (2) and (3) of Shin (1993), respectively, for shallow earthquakes $(h \leq$ $35 \mathrm{~km}$ ). If we take the form $Q=\pi f / \gamma U$, as the seismic quality factor, where $f$ is the frequency of the wave, and $U$ is its velocity. The seismic quality factors from Eqs. (7) and (8) are 129 and 221, respectively, by assuming $f=1.25 \mathrm{~Hz}$ and $U=3.3 \mathrm{~km} \mathrm{~s}^{-1}$ for averaged $\mathrm{S}$ wave speed in the crust. On the other hand, the seismic quality factors from Eq. (2) are 72 and 198, respectively. The new attenuation functions show slightly lower seismic energy decay (higher $Q$ ) than the old ones. If we consider deep earthquakes $(h>35 \mathrm{~km})$, either Eqs. (9) or (10) obtained in this study has much lower attenuation than Eq. (3). The seismic quality factors from Eqs. (9) and (10) are 555 and 242, respectively, by assuming $f=1.25 \mathrm{~Hz}$ and $U=4.0 \mathrm{~km} \mathrm{~s}^{-1}$ for averaged $\mathrm{S}$ wave speed in the crust, whereas $Q$ value from Eq. (3) is 130. In general, $Q$ values are larger toward to deeper depths. For example, $Q s$ values range from around 100 to 500 above $35 \mathrm{~km}$ depths and below $35 \mathrm{~km}$ depths $Q s$ values are much higher than 500 for the Taiwan region based on 3D $Q$ tomography (Wang et al. 2010). The $Q$ values obtained in this study are consistent with those from previous studies (Wang et al. 2010). Also, $Q$ values between the northern and southern deep earthquakes are very different, which shows the need for distinguishing deep earthquakes to two regimes.

Based on the new attenuation functions [Eqs. (7) to (10)], we can obtain the new $M_{L}$ [Eq. (1)] for 692 events to compare with the old $\mathrm{M}_{\mathrm{L}}$ and $\mathrm{M}_{\mathrm{W}}$ (Fig. 5). Figure 5a shows that the new $\mathrm{M}_{\mathrm{L}}$ is smaller than the old one, especially toward to larger magnitudes. For example, the $M_{L} 6.9$ earthquake originally reported by CWB as mentioned in Introduction is adjusted to $\mathrm{M}_{\mathrm{L}} 6.1$ after applied the new attenuation functions. On the other hand, the USGS moment magnitude of this earthquake is 6.4 , which is closer to the new $\mathrm{M}_{\mathrm{L}}$. Furthermore, Fig. 5b shows that the relationship between the new $M_{L}$ and $M_{W}$ (USGS) is around 1:1 for magnitudes greater than 4 , which is consistent with the observations (Kanamori 1983; Hanks and Boore 1984; Havskov and Ottemöller 2010). Also, both the distributions of mb (USGS) and $\mathrm{M}_{\mathrm{W}}$ (USGS) versus the new $\mathrm{M}_{\mathrm{L}}$ plots are more clustered than those versus the old $\mathrm{M}_{\mathrm{L}}$, especially toward to larger magnitudes (Figs. 2 and $5 b$ ). Figures $5 \mathrm{c}$ and d show the old $\mathrm{M}_{\mathrm{L}}$ and new $\mathrm{M}_{\mathrm{L}}$ subtract with $\mathrm{M}_{\mathrm{W}}$ (USGS) and mb, respectively. The new $M_{L}$ values are closer to the $M_{W}$ (USGS) and $\mathrm{mb}$ (USGS) values than the old $\mathrm{M}_{\mathrm{L}}$ ones.

For the comparison among other magnitudes $\left[\mathrm{M}_{\mathrm{W}}(\mathrm{Au}-\right.$ toBATS), new $\mathrm{M}_{\mathrm{L}}$, and old $\mathrm{M}_{\mathrm{L}}$ ], the $\mathrm{M}_{\mathrm{W}}$ (AutoBATS) (Jian et al. 2018) have a good agreement with $\mathrm{M}_{\mathrm{W}}$ (USGS), and the old and new $\mathrm{M}_{\mathrm{L}}$ have higher values than $\mathrm{M}_{\mathrm{W}}$ (USGS) for magnitude 4 to 6 (Fig. 6). Around magnitude 4 to 6 , the old and new $\mathrm{M}_{\mathrm{L}}$ are about 0.4 and 0.2 units higher than both $\mathrm{M}_{\mathrm{W}}$ (AutoBATS) and $\mathrm{M}_{\mathrm{W}}$ (USGS), respectively. Previous studies have shown that the old $\mathrm{M}_{\mathrm{L}}$ is 0.2 unit higher than $\mathrm{M}_{\mathrm{W}}$ 

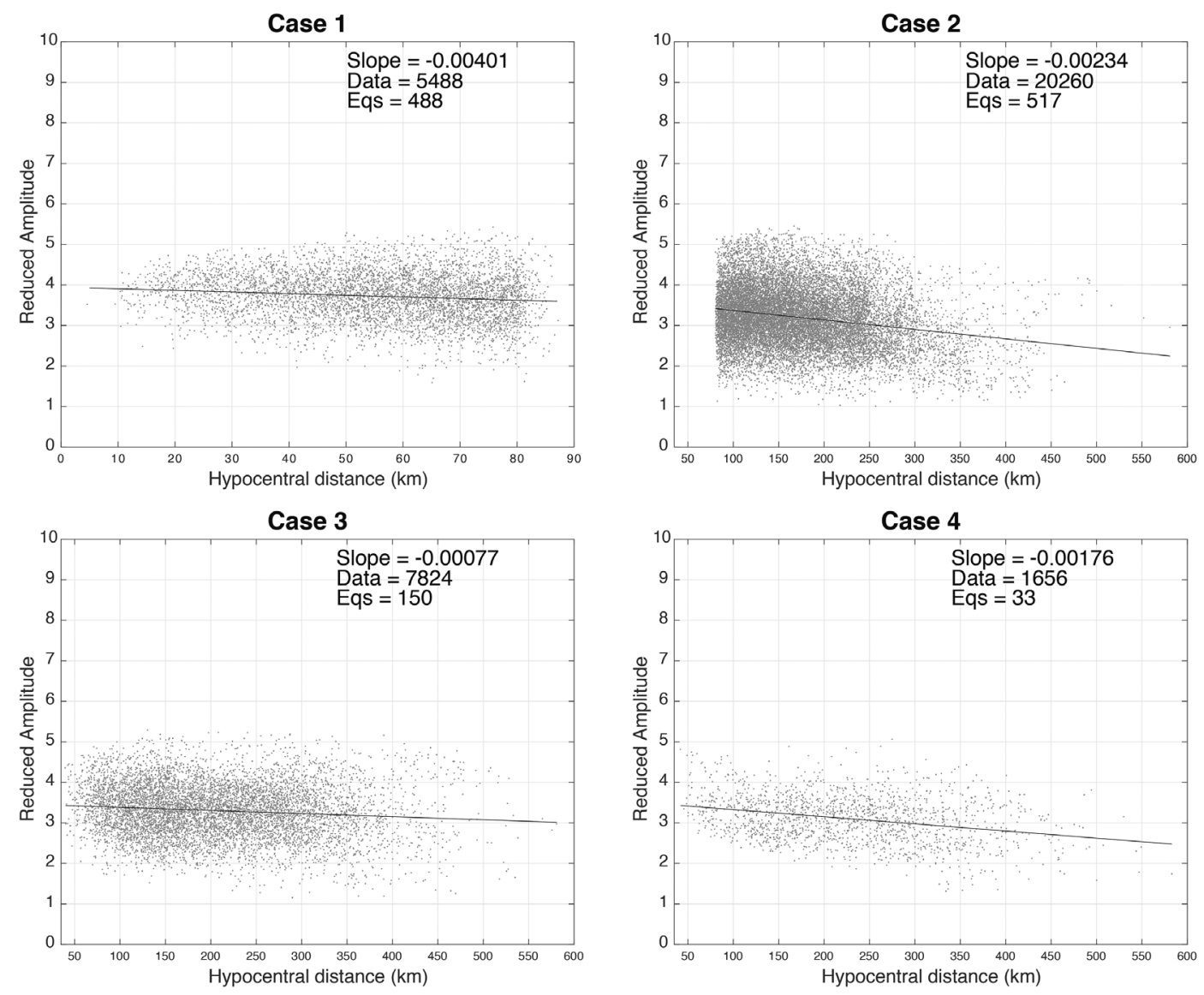

Fig. 3. Reduced amplitude versus hypocentral distance for four cases.

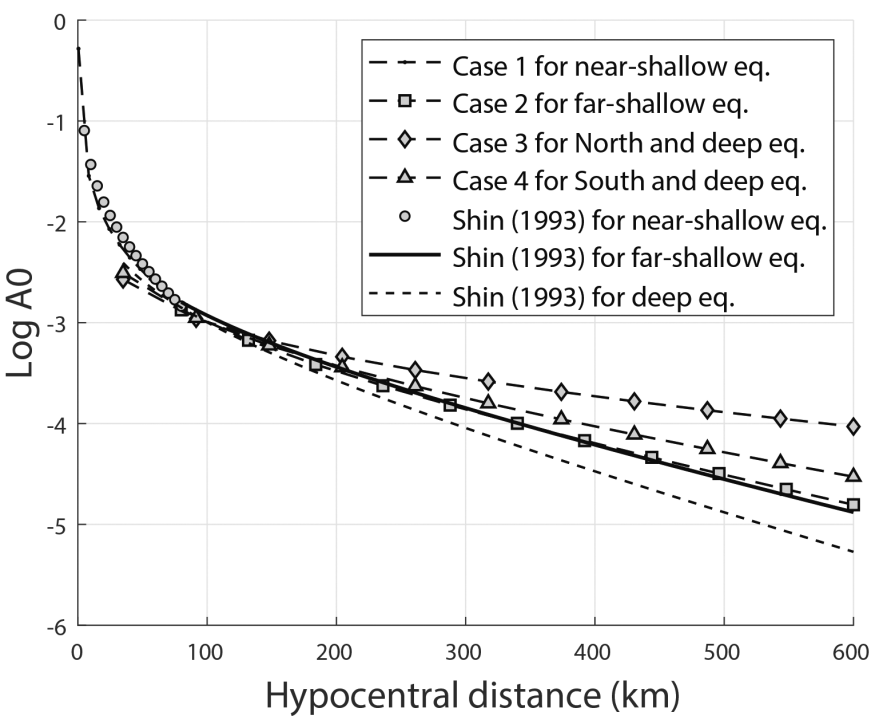

Fig. 4. The attenuation functions, $\log A_{0}(\Delta)$, obtained in this study and Shin (1993). 
(a)

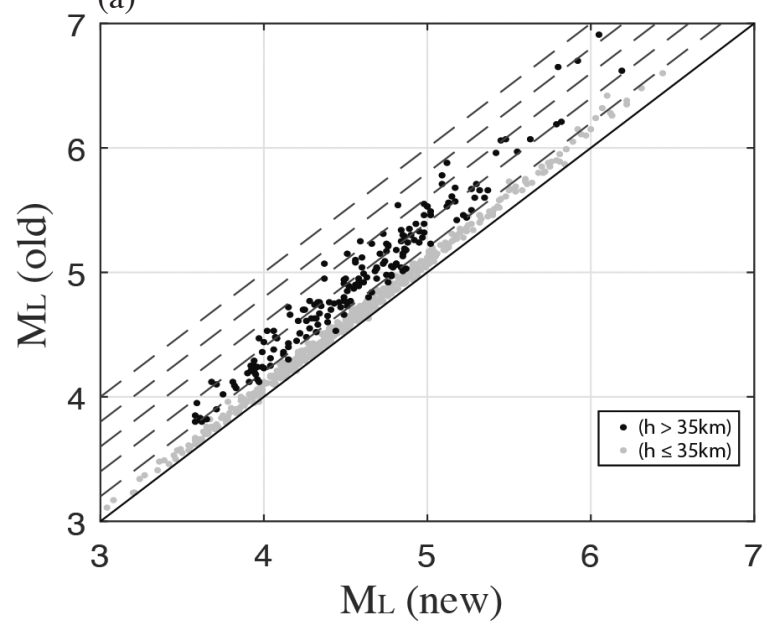

(c)

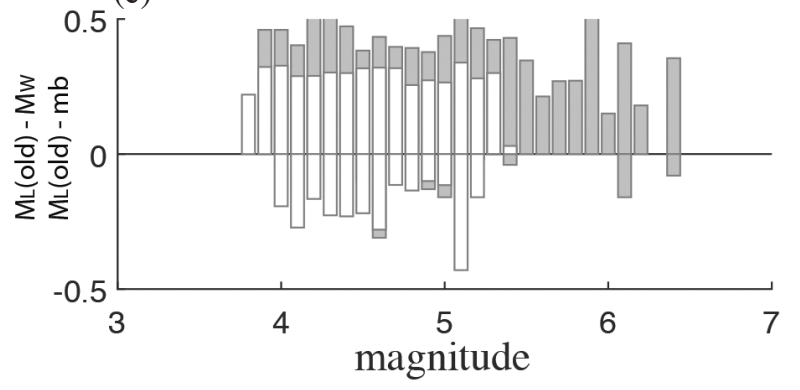

(b)

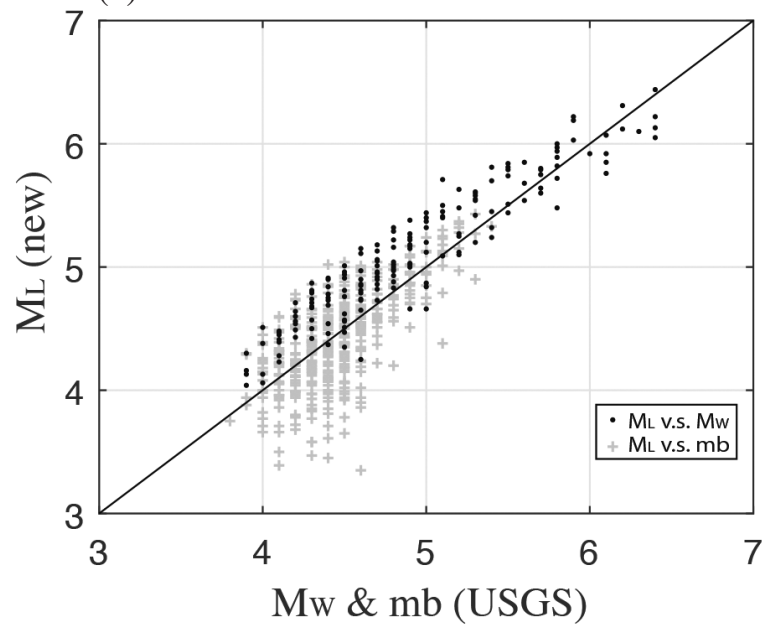

(d)

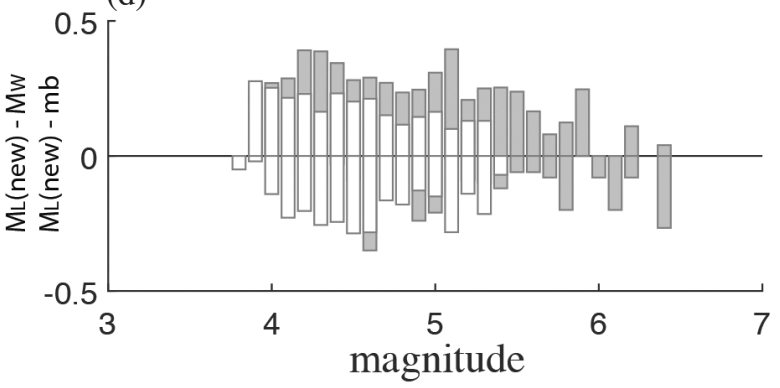

Fig. 5. The comparison of $M_{L}$ (new) and other magnitudes [ $M_{L}$ (old), $M_{W}$ (USGS), and mb (USGS)]. (a) $M_{L}$ (old) versus $M_{L}$ (new). Gray dot: focal depth $\leq 35 \mathrm{~km}$ (Cases 1 and 2). Black dot: focal depth $>35 \mathrm{~km}$ (Cases 3 and 4). $\mathrm{M}_{\mathrm{L}}$ (new): $\mathrm{M}_{\mathrm{L}}$ determined by the attenuation functions from this study. Dashed line: every 0.2 increment with the slope 1. (b) $\mathrm{M}_{\mathrm{L}}$ (new) versus $\mathrm{M}_{\mathrm{W}}$ (USGS) and $\mathrm{mb}$ (USGS). (c) The spread ranges of $\mathrm{M}_{\mathrm{L}}$ (old) - $\mathrm{M}_{\mathrm{W}}$ (USGS) (gray bar) and $\mathrm{M}_{\mathrm{L}}$ (old) - mb (USGS) (white bar) for each magnitude bin. (d) The spread ranges of $\mathrm{M}_{\mathrm{L}}$ (new) - $\mathrm{M}_{\mathrm{W}}$ (USGS) (gray bar) and $\mathrm{M}_{\mathrm{L}}$ (new) - mb (USGS) (white bar) for each magnitude bin.

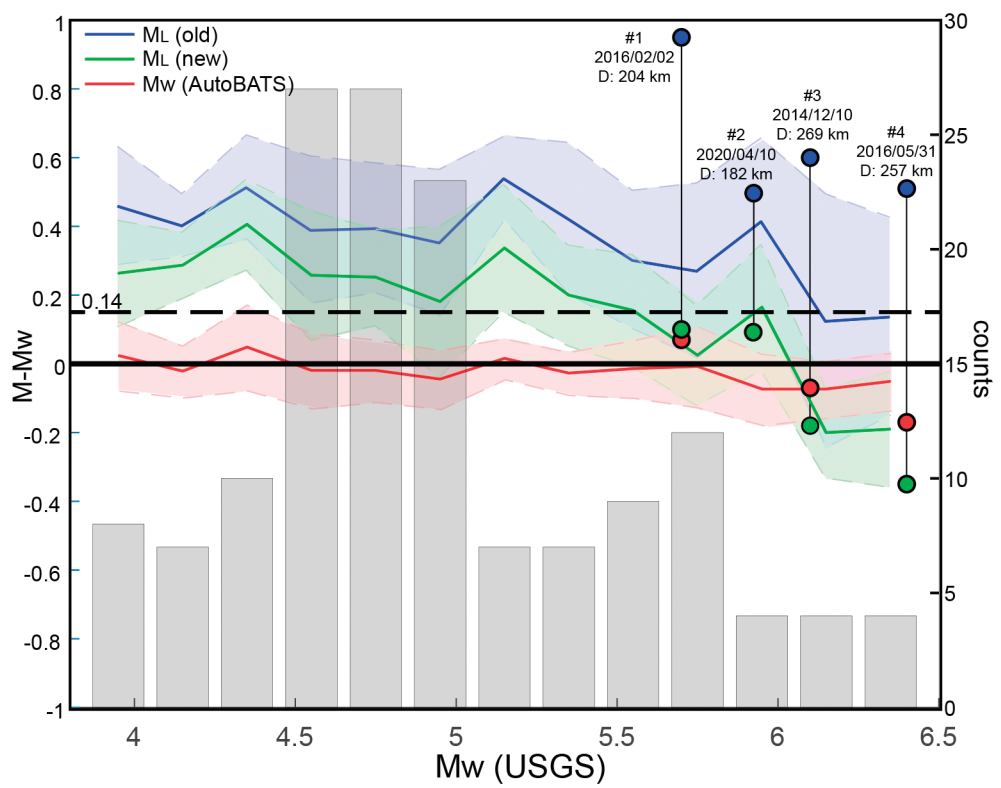

Fig. 6. The magnitudes $\left[M_{W}\right.$ (AutoBATS), $M_{L}$ (new), and $M_{L}$ (old)] comparison with respect to $M_{W}$ (USGS). The red, green and blue lines and polygons indicate the averaged discrepancy values and standard deviations for $\mathrm{M}_{\mathrm{W}}$ (AutoBATS), $\mathrm{M}_{\mathrm{L}}$ (new), and $\mathrm{M}_{\mathrm{L}}$ (old), respectively. The 0.14 dashed line indicates the possible overestimated unit for the calculation of the maximum amplitude by CWB with respect to that by the definition of Richter (1935). Circles with red, green, and blue colors are the magnitudes of the deep earthquakes determined by $M_{W}$ (AutoBATS), $M_{L}$ (new), and $\mathrm{M}_{\mathrm{L}}(\mathrm{old})$, respectively. 
for the crustal events $(h<35 \mathrm{~km})$ (Wu et al. 2005; Lee et al. 2014; Jian et al. 2018). In this study, we included both shallow and deep earthquakes for analysis. As a result, the old $M_{L}$ is 0.4 unit larger than $M_{W}$, which is even larger than the study by Wu et al. (2005). After applying the new attenuation functions in this study, the new $\mathrm{M}_{\mathrm{L}}$ is down to 0.2 unit larger than $\mathrm{M}_{\mathrm{W}}$. The 0.2 unit discrepancy between the new $\mathrm{M}_{\mathrm{L}}$ and $\mathrm{M}_{\mathrm{W}}$ could result from two factors, the calculation of maximum amplitudes and earthquake locations. Considering the calculation of maximum amplitudes by CWB, the root sum squared of peak amplitudes in the north-south and east-west components, could lead to 1.4 times larger than the definition of the calculation of maximum amplitudes by Richter (1935), which the maximum amplitude is averaged from two horizontal components. As a result, the new $\mathrm{M}_{\mathrm{L}}$ is 0.14 unit larger than $\mathrm{M}_{\mathrm{w}}$. The other factor, the discrepancy of earthquake locations determined by CWB and USGS, could lead to at least $\sim 0.06$ unit discrepancy between the new $\mathrm{M}_{\mathrm{L}}$ and $\mathrm{M}_{\mathrm{W}}$ (USGS). This can be also shown by the trends of the systematical variations of the old $\mathrm{M}_{\mathrm{L}}$, the new $\mathrm{M}_{\mathrm{L}}$, and $\mathrm{M}_{\mathrm{W}}$ (AutoBATS) with respect to $\mathrm{M}_{\mathrm{W}}$ (USGS). For magnitude greater than 6 , the phenomenon of $\mathrm{M}_{\mathrm{L}}$ saturation as the effect of Wood-Anderson simulator can be obviously observed in the new $M_{L}$ (Fig. 6), which is reasonable for the relationship between $\mathrm{M}_{\mathrm{L}}$ and $\mathrm{M}_{\mathrm{W}}$ (Hanks and Boore 1984; Deichmann 2006). Four deep earthquakes (focal depths greater than $150 \mathrm{~km}$ ) determined by the new attenuation functions as examples to show the main contribution of this study, especially for deep earthquakes. Events \#1, \#3, and \#4 occurred in northeastern offshore of Taiwan, and \#2 occurred in southeastern offshore. In these cases, the discrepancies between the old and new $\mathrm{M}_{\mathrm{L}}$ can reach as large as 1 and the old $\mathrm{M}_{\mathrm{L}}$ is also significantly larger than $\mathrm{M}_{\mathrm{W}}$ (Fig. 6).

$\log S$ for each station can be evaluated by using the form $\log S=\log A_{\text {red }} / A_{\text {avg }}=\Delta \mathrm{M}_{\mathrm{L}}$, where $A_{\text {rec }}$ is the amplitude from the simulated Wood-Anderson seismograph from the seismograph recorded in one seismic station and $A_{\text {avg }}$ is the averaged amplitude from the simulated Wood-Anderson seismographs from the seismograph recorded in the seismic network (Fig. 7). $\Delta \mathrm{M}_{\mathrm{L}}$ values are related to site effects and radiation patterns. For the first order in all of the cases, the seismic stations in western Taiwan have large positive $\Delta \mathrm{M}_{\mathrm{L}}$

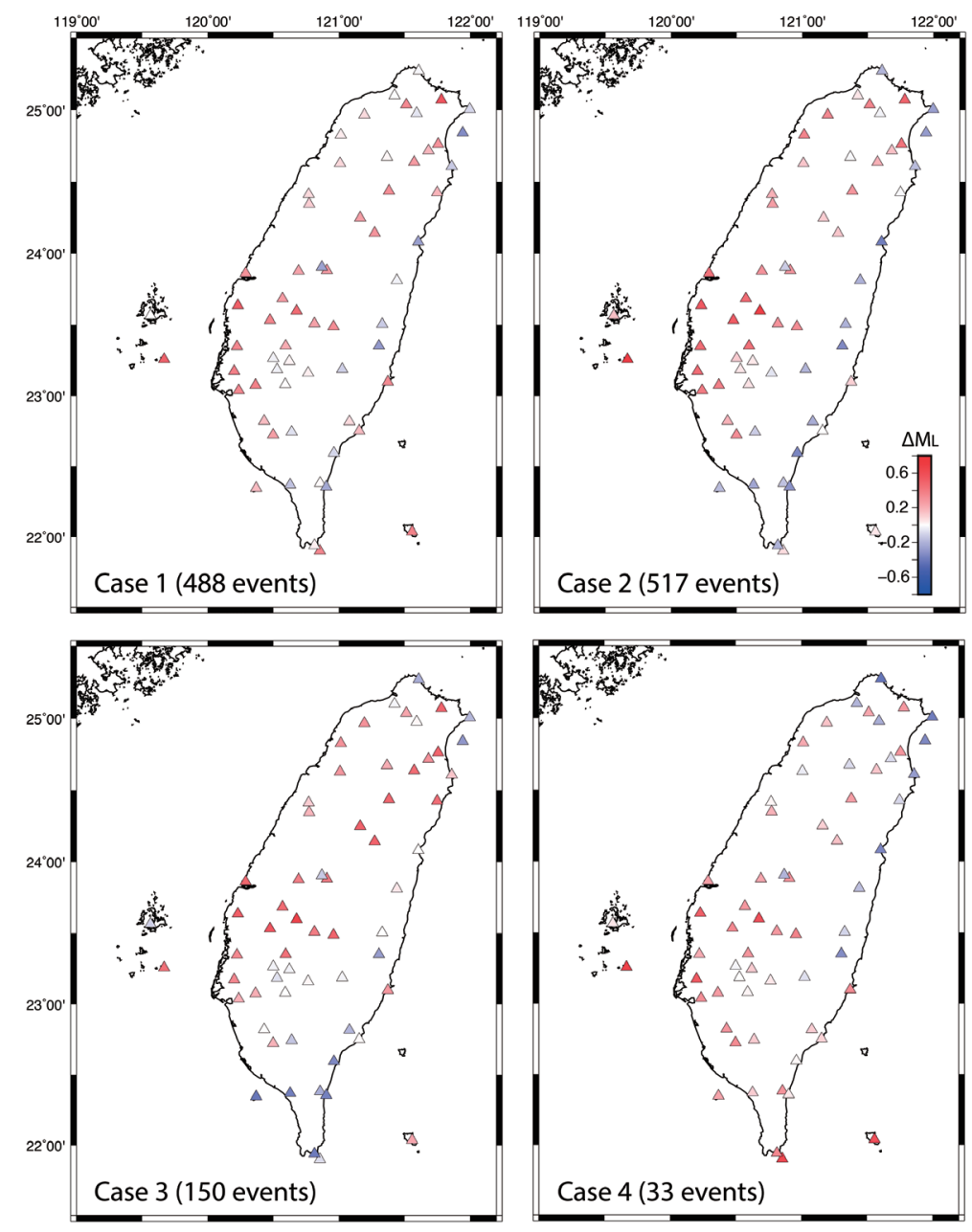

Fig. 7. $\log S$ obtained from different cases. 
values due to local site effects. $\Delta \mathrm{M}_{\mathrm{L}}$ values of Cases 3 and 4 not only represent local site effects but also ray paths from north and south for deep earthquakes, respectively.

\section{CONCLUSIONS}

We obtained new attenuation functions from the new data set of the CWBSN24 for the calculation of $\mathrm{M}_{\mathrm{L}}$ in Taiwan. For shallow earthquakes $(h \leq 35 \mathrm{~km})$, the new attenuation functions are similar to those proposed by Shin (1993), whereas for deep earthquakes $(h>35 \mathrm{~km})$ the new attenuation functions show significantly higher $Q$ values. After applied the new attenuation functions, the new $\mathrm{M}_{\mathrm{L}}$ values have better relationships with the $m b$ and $\mathrm{M}_{\mathrm{W}}$ values than the old ones. The new attenuation functions can be easily implemented to the official earthquake reports for the calculation of $\mathrm{M}_{\mathrm{L}}$.

Acknowledgements This project is supported by the Central Weather Bureau (CWB), Taiwan (MOTC-CWB108-E-06). The assistances for the data preparation by Dr. Y. J. Hsu of National Central University and Ms. M. Y. Ho and Mr. C. W. Ho of the Central Weather Bureau are highly appreciated. We also thank Dr. C.-H. Chang of National Central University for the constructive comments.

\section{REFERENCES}

Chang, C.-H., Y.-M. Wu, D.-Y. Chen, T.-C. Shin, T.-L. Chin, and W.-Y. Chang, 2012: An examination of telemetry delay in the Central Weather Bureau Seismic Network. Terr. Atmos. Ocean. Sci., 23, 261-268, doi: 10.3319/TAO.2011.11.29.01(T). [Link]

Deichmann, N., 2006: Local magnitude, a moment revisited. Bull. Seismol. Soc. Am., 96, 1267-1277, doi: 10.1785/0120050115. [Link]

Hanks, T. C. and D. M. Boore, 1984: Moment-magnitude relations in theory and practice. J. Geophys. Res., 89, 6229-6235, doi: 10.1029/JB089iB07p06229. [Link]

Havskov, J. and L. Ottemöller, 2010: Routine Data Processing in Earthquake Seismology: With Sample Data, Exercises and Software, Springer, Dordrecht, 347 pp, doi: 10.1007/978-90-481-8697-6. [Link]

Jian, P.-R., T.-L. Tseng, W.-T. Liang, and P.-H. Huang, 2018: A new automatic full-waveform regional moment tensor inversion algorithm and its applications in the Taiwan area. Bull. Seismol. Soc. Am., 108, 573587, doi: 10.1785/0120170231. [Link]

Kanamori, H., 1983: Magnitude scale and quantification of earthquakes. Tectonophysics, 93, 185-199, doi: 10.1016/0040-1951(83)90273-1. [Link]

Lee, S.-J., W.-T. Liang, H.-W. Cheng, F.-S. Tu, K.-F. Ma, H. Tsuruoka, H. Kawakatsu, B.-S. Huang, and C.-C. Liu, 2014: Towards real-time regional earthquake simulation I: Real-time moment tensor monitoring (RMT) for regional events in Taiwan. Geophys. J. Int., 196, 432-446, doi: 10.1093/gji/ggt371. [Link]

Richter, C. F., 1935: An instrumental earthquake magnitude scale. Bull. Seismol. Soc. Am., 25, 1-32.

Shin, T.-C., 1993: The calculation of local magnitude from the simulated Wood-Anderson seismograms of the short-period seismograms in the Taiwan area. Terr. Atmos. Ocean. Sci., 4, 155-170, doi: 10.3319/ TAO.1993.4.2.155(T). [Link]

Wang, Y.-J., K.-F. Ma, F. Mouthereau, and D. EberhartPhillips, 2010: Three-dimensional $Q p$ - and $Q s$-tomography beneath Taiwan orogenic belt: Implications for tectonic and thermal structure. Geophys. J. Int., 180, 891-910, doi: 10.1111/j.1365-246X.2009.04459.x. [Link]

Wu, Y.-M., R. M. Allen, and C.-F. Wu, 2005: Revised $M_{\mathrm{L}}$ determination for crustal earthquakes in Taiwan. Bull. Seismol. Soc. Am., 95, 2517-2524, doi: 10.1785/0120050043. [Link] 